\title{
Analysis on the Coverage Extension Policy of Basic Endowment Insurance for Urban Workers in China
}

\author{
Yongyong Sun ${ }^{1, a}$, Qianwen $\mathrm{Xu}^{2, \mathrm{~b}}$ \\ ${ }^{1}$ Department of Social Security, School of Public Administn, Central China Normal University, \\ Wuhan, China \\ ${ }^{2}$ Department of Social Security, School of Public Administn, Central China Normal University, \\ Wuhan, China \\ ayongyongs@mail.ccnu.edu.cn , ${ }^{\mathrm{b}}$ nazimix@126.com
}

\begin{abstract}
Keywords: basic endowment insurance for urban workers, coverage extension policy, evaluation research, financial sustainability, government, China

Abstract. It has been the work focus of Chinese government to extend the coverage of basic endowment insurance for urban workers, and it prompted a rapid growth of the fund's income and accumulated balance. This improves the financial sustainability of the system temporarily, and increases the future responsibility of payment. With the shrinking of extension potentiality and the rapid aging of the extension object, it will become increasingly difficult to improve the financial sustainability of the system relying on the extension. In this situation, the Chinese government should adjust the work focus to strengthening the financial sustainability of the system through a variety of methods, mainly including improving basic financial system, adjusting the key parameters, establishing fund reserve and perfecting the management and investment and other works.
\end{abstract}

\section{Introduction}

In order to implement the basic principle of "wide coverage", the Chinese government has regarded the extension as the work focus of the reform of basic endowment insurance system for urban workers. For example, in an important reform legislation enacted in 2005, the State Council of China required clearly, "at present and for a period in the future, the coverage extension of basic endowment insurance should focus on non-public enterprises, urban individual businesses and flexible employees "[1]. Therefore, the government's extension has achieved remarkable results. By the end of 2014, the total number of the insured has reached 341 million, about three times the number of participants in 1998 when the new system began to implement[2]. It is expected that the government will continue to promote the extension work in the next years, because "wide coverage" is still regarded as one of the four major principles of social security by the national "Twelfth Five Year " plan[3], and Social Security "Twelfth Five Year " Planning Outline puts forward the target of insured number of basic endowment insurance for urban workers[4]. However, the constant extension of coverage will have a profound impact on the financial sustainability of basic endowment insurance. It will increase the current collection of income, and continue to accumulate pension debts of the system. More importantly, the potentiality of extension is depleting, while other more important issues have been imminent. Therefore, the government should adjust the focus of work promptly.

For a long time, the academia in China has made a lot of research on the coverage ratio and the extension of the endowment insurance system for urban workers. For example, Zhu Dongmei (2005) used an actuarial model to calculate the number of people that should be covered in the future to make up the income gap in the perspective of the balanced budget of pension fund, and demonstratiod the feasibility of extension. She analyzed the actual problems encountered in the current extension of coverage from three aspects of the enterprises, policy implementation institutions and workers, and put forward some suggestions and countermeasures[5]. Wang Hongcai (2012) analyzed the necessity and nality of extending the coverage of endowment insurance on the basis of the current coverage of basic endowment insurance for urban workers in China, dissected the factors that affect the implement of extension. He claimed to start work on making laws, defining the responsibilities of government, 
strengthening the open and management of endowment insurance fund and reforming public institutions, etc. He proposed that the coverage extension should concentratio on the insurance work of non-public enterprises, urban individual businesses and flexible employees[6]. At the same time, the financial risks and sustainability of basic endowment insurance for urban workers have also been the concern of scholars. For example, Wang Xiaojun (2002) made an actuarial evaluation on the basis of the existing policies and its implementation, predicted the future financial situation of the system, and then provided some recommendations to deal with the financial risks[7]. Sun Yongyong and Shi Lei (2012) analyzed the financial risk sources of basic endowment insurance system for urban workers, and pointed out that the current system is faced with some financial risks brought by the deceleratiod economic growth, the fuzzy disposal of transition cost, the aging population and other factors. They thought these risks could be dealt with by improving the system design, establishing some special asset reserves, setting up a financial transfer payment mechanism and other measures[8]. In order to deal with the problems of financial sustainability, more and more attention has been paid to the top-level design of the system, the adjustment of parameters and the fund management. Overall, in the current relative studies, most are exploring these problems respectively, few are exploring these problems comprehensively. In view of this, this paper tries to combine the coverage extension with the financial sustainability, top-level design of the system, parameters' adjustment, fund management and other aspects to investigate the change of government's work focus in the reform of basic endowment insurance for urban workers.

\section{Extension Improves the Financial Sustainability of Basic Endowment Insurance System for Urban Workers Temporarily.}

China has continued to extend the coverage of basic endowment insurance system for urban workers. Its main goal should be making the laborers and their families as much as possible to get basic endowment security, but it may also care about improving the financial sustainability of the system. From a national perspective, the extension does also improve the financial sustainability of basic endowment insurance system for urban workers in the short term.

The Coverage Extension Policy Has Improved the Insured Structure, and Stabilized the System Dependency ratios. First of all, from the perspective of urban workers' insured status, the system dependency ratios keep steady generally in the last 10 years, which can be mainly attributed to the coverage extension. As shown in Figure 1, from 2001 to 2014, the system dependency ratios of basic endowment insurance system for urban workers fluctuated, but its range was small, between $31 \%$ to $34 \%$. This is very commendable in the context of a rapidly aging population in China. This achievement is mainly due to the vigorous promotion of extension by government for so many years. Between 2001 and 2011, excluding 2002 and 2009, the number of insured workers in other years grew quickly, and the growth ratios increased from $3.39 \%$ to $11.15 \%$, which was much higher than the growth ratios of the number of retirees in the same period. Secondly, the coverage extension of basic endowment insurance system for urban workers from the corporate sector to other sectors has also helped to reduce the whole system dependency ratios. For example, between 2010 and 2012, the system dependency ratios of corporate sector were $36.10 \%, 33.61 \%$ and $33.96 \%$ respectively, while the ratios of other personnel sector were $21.31 \%, 25.13 \%$ and $29.69 \%$ respectively[9]; But in 2011 and 2012, the growth ratios of the insured number in corporate sector were $10.20 \%$ and $6.15 \%$ respectively, while the ratios in other personnel sector were $14.87 \%$ and $12.48 \%$ respectively[10]. Finally, in the corporate sector, the initial insured workers were mainly the formal workers of state-owned enterprises, then followed by the collective enterprise workers, and the last insured workers were the workers of Hong Kong, Macao, Taiwan and foreign enterprises, and the workers of other enterprises with various economic types. By the end of 2014, the insured number of other enterprises with various economic types reached 115.09 million, which was more than the insured worker number of state-owned enterprises by about 32.82 million. And the insured worker number of Hong Kong, Macao, Taiwan and foreign companies was also increasing, which was more than the 
insured worker number of collective enterprises by 1.66 million. From the view of age structure of the insured, the system dependency ratios of those who worked in state-owned enterprises and collective enterprises kept at a high level in the long-term. From 2010 to 2014, the system dependency ratios of state-owned enterprises continued rising, from $65.02 \%$ to $68.54 \%$, while in the same period, the system dependency ratios of collective enterprises had been in the first place, ranging from $68.94 \%$ to $75.18 \%$. In contrast, the system dependency ratios of the insured workers of other enterprises with various economic types and Hong Kong, Macao, Taiwan and foreign enterprises had been still at a low level. From 2010 to 2014, the dependency ratios of other enterprises with various economic types had been maintained at about 15\%, and the system dependency ratios of Hong Kong, Macao, Taiwan and foreign enterprises had been remained between 3\% to 4\%[11]. This is the basic reason why recent years the system dependency ratios of basic endowment insurance system have been still in a downward trend in the business sectors in recent years, though in the background of the aggravation of aging population.

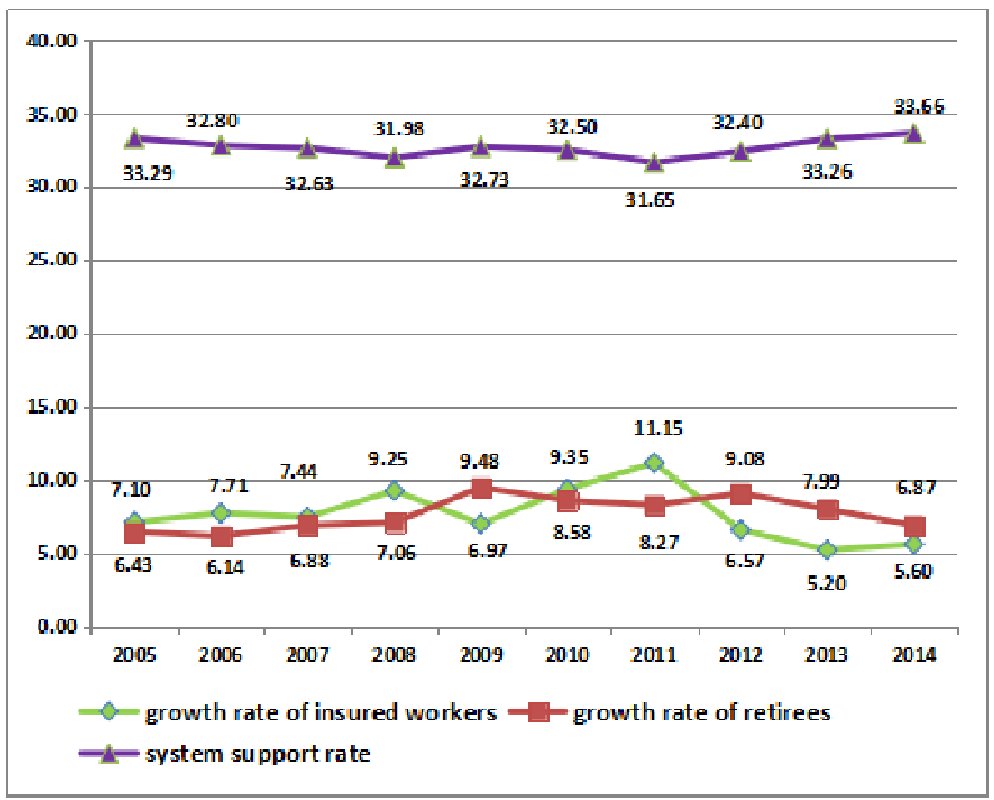

Figure 1. The insured status of basic endowment insurance for urban workers (\%), 2005-2014

Data source: Ministry of Human Resources and Social Security of the People' Republic of China, "2005-2014 Labor and Social Security Career Development Statistical Bulletin".

\section{The Extension Policy Has Promoted the Rapid Growth of the Current Balance and} Cumulative Balance of Pension Fund, and Has Increased the Payable Months of Funds.

Extension work by the government, the number of insured workers of basic endowment insurance for urban workers has maintained a rapid growth, which brought about the rapid growth of the number of contributory persons. The contributory base has also maintained a rapid growth because of the rapid increase of social average wage. All of them make the collection of income grow quickly as the main source of the endowment insurance fund. In 1989, the income of China's basic endowment insurance fund for urban workers was only about 14.68 billion yuan, and by the end of 2014, the fund's income had increased to 2530.97 billion yuan. During this period, excluding the deficit in 1998, there were some current balances in other years. At the same time, the accumulated balance of China's basic endowment insurance fund for urban workers grew more rapidly. It was only about 68.99 billion yuan in 1989, while it reached 3180 billion yuan by the end of 2014[12]. The rapidly growing accumulated balance ensures the constant raise of the payment capacity of basic endowment insurance system for urban workers. From 2006 to 2012, the number of payable months of China's basic endowment insurance fund for urban workers has raised from 13.6 to 18.46. Especially, the number of payable months had been up to 50.68 in Guangdong Province in 2014[13]. 


\section{The Extension Is Facing with Some Challenges}

The Chinese government should not continue to take the extension as the reform focus of basic endowment insurance system for urban workers.

The Coverage Extension Will Be Decreasingly Potential and Increasingly Difficult. After these years of coverage extension, the workers in all kinds of large and medium-sized enterprises have mainly participated in basic endowment insurance system for urban workers by far. Many workers in small business employees, individual businesses and free professionals with strong contribution capacity have also joined in. The remaining potential group who have not yet joined in are mostly workers with poor contribution capacity and weak willingness to participate, and thus they mainly belong to "a hard nut to crack" of the extension work. Throughout the numbers of remaining urban workers who had not participated in basic endowment insurance during 2005 to 2014 (Here is shown as the numbers of urban workers minus the numbers of insured workers that joined in basic endowment insurance for urban workers, and hereinafter referred to as the uninsured numbers). It can be found that from 2007 to 2014, except for a small increase in 2009, the uninsured numbers decreased in other years (see Figure 2). This means the potential space of future extension of basic endowment insurance for urban workers is shrinking. Besides, in the long run, the extension will have the end of the day, and "the window of opportunity" for coverage extension will be gradually closed.

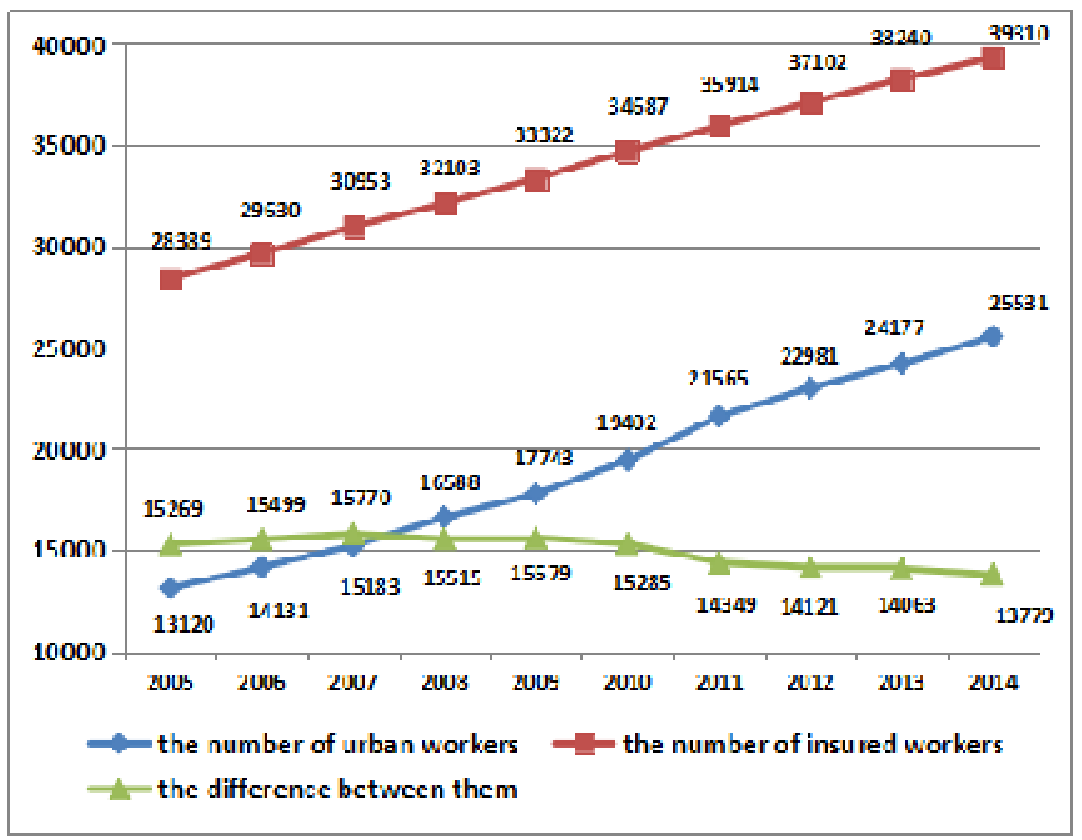

Figure 2. The numbers of urban employment and the insured situation (Unites: one million), 2005 - 2014

Date source: Ministry of Human Resources and Social Security of the People' Republic of China, "2005-2014 Labor and Social Security Career Development Statistical Bulletin".

Note: the number of people that had not participated in basic endowment insurance for urban workers is equal to the number of urban workers minus the number of insured workers. But due to the different statistical caliber, not all insured are urban workers, and not all urban workers have participated in the system. But this has little influence on the conclusion that the change of coverage had resulted in the reduction of the workers who would be potentially covered.

With the Aging Population Peak Looming, the Workers Who Will Be Potentially Covered Are Also Rapidly Aging. As the aging population peak is quickly approaching, the age structure of China's population is changing rapidly. From 2004 to 2013, the proportion of population aged 0-14 reduced fast in China, from $21.50 \%$ to $16.41 \%$. On the contrary, the scale of the elderly population expanded rapidly, and the proportion of the population aged over 65 accounted for the total population 
rose from $7.58 \%$ to $9.67 \%$. The proportion of active labor force was still rising, and the proportion of population aged 15-64 rose from $35.27 \%$ to $58.94 \%$ (see Figure 3). But according to the prediction of UN Population Division, the scale of active labor force aged 15 - 64 in China will reduce year by year when it reaches a peak of 9.96 million people in 2015, 981 million people in 2025, 909 million in 2035, 829 million in 2045, and 734 million in 2055. On the other hand, the scale of the elderly population aged 65 will increase year by year, from 130 million in 2015 to 229 million in 2030 and 323 million in 2045 (United Nations Population Division, 2010)[14]. In the entire process of the age structure's change of population, the uninsured group can't be immune, and they will be aging quickly too. Due to the lack of relevant data, it is difficult to predict the aging trend of the uninsured group, but it can be concluded that there will be such a time point that relying on extension could neither improve the insured structure of basic endowment insurance system for urban workers nor reduce the system dependency ratio substantially. Moreover this time point is expected to come soon.

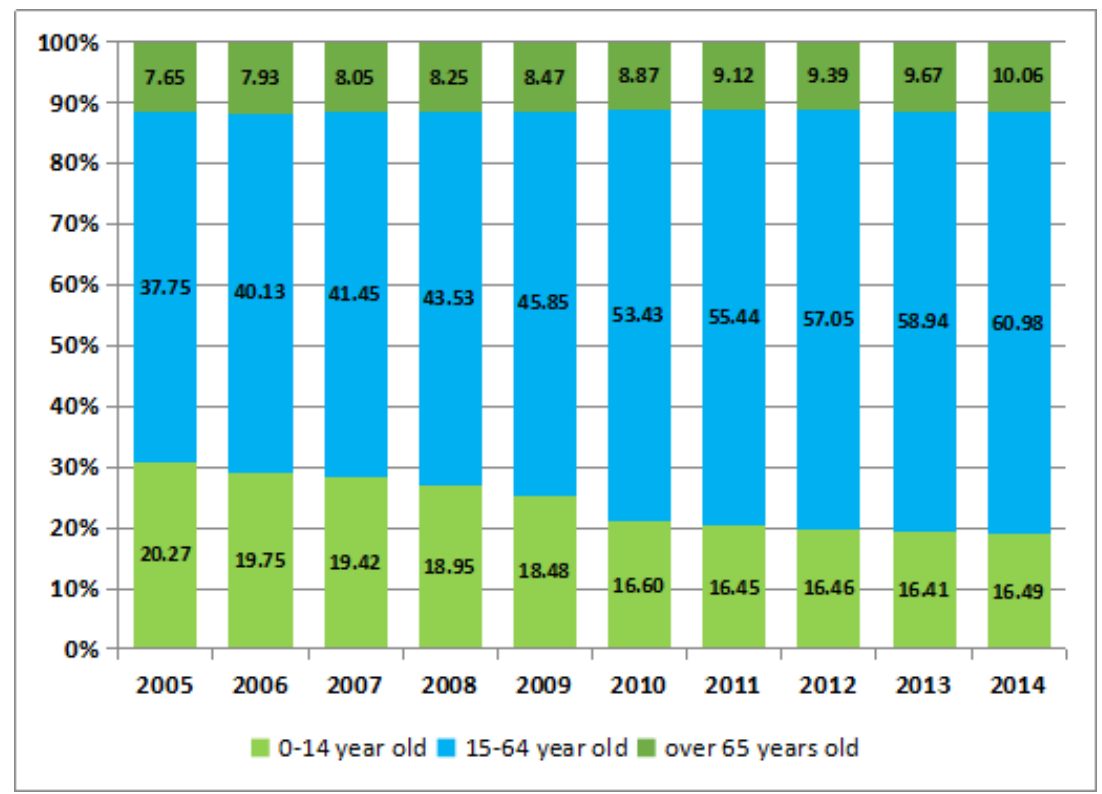

Figure 3. The age structure's change of population in China, 2005-2014

Data source: National Bureau of Statistics. China Statistical Yearbook 2014[Z]. Beijing: China Statistics Press, 2014 Table 3 - 3

Some Undesirable Signs Are Already There. Firstly, from the perspective of the insured situation, from 2012 to 2014, the system dependency ratio of basic endowment insurance system for urban workers had increased for three consecutive years, and the basic reason is that growth ratios of insured workers' number in the same period decreased rapidly, below the growth ratio of the retired population (see Figure 1). Secondly, continuing to extend the coverage hasn't contributed to the stability of the system dependency ratio any more. The system dependency ratio of institutions and banks had exceeded that of enterprises in 2012, and the system dependency ratio of other personnel had reached $33.90 \%$ in 2013, nearly 1 percentage point higher than that of enterprises. In 2014, the system dependency ratio of other personnel had been as high as $38.84 \%$, more than 7 percentage points higher than that of enterprises. The system dependency ratio of institutions and banks was much higher than that of enterprises, and only the system dependency ratio of government was slightly lower than that of enterprises[15]. Finally, more and more people lack of sustainable contribution capacity are pulled into basic endowment insurance for urban workers by powerful extension, which causes a constant rise of the proportion that the number of non-contribution workers accounts for the number of insured workers. The proportion was $10.02 \%$ in 2006, and rose to $18.81 \%$ in 2014 (see Figure 4). 


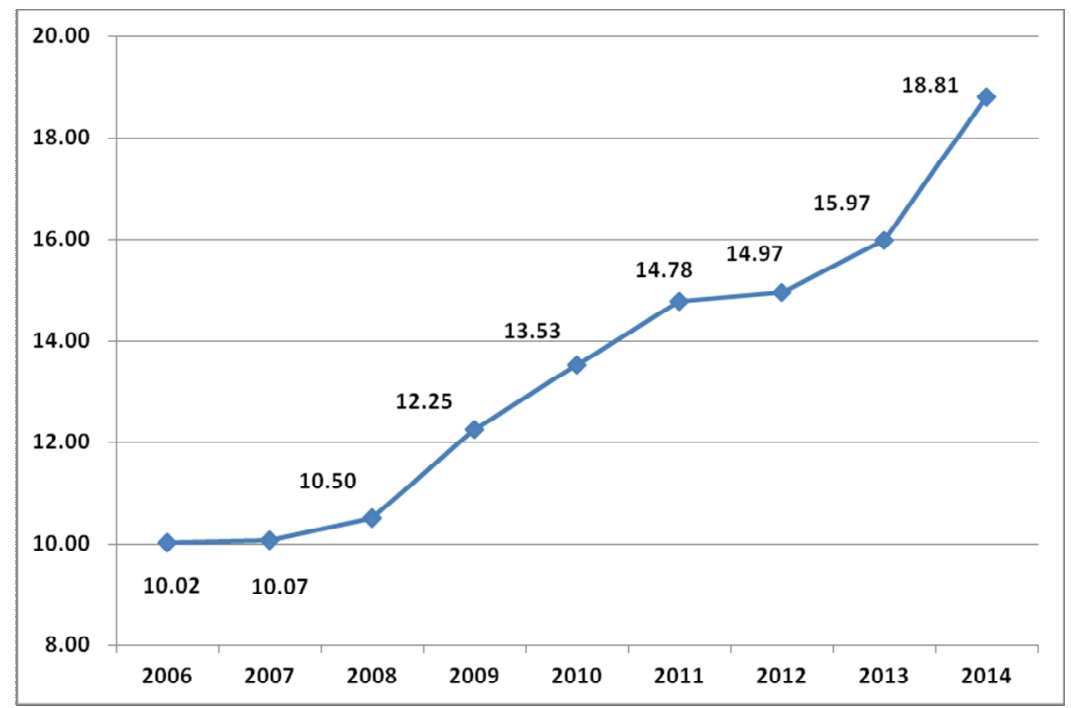

Figure 4. The proportion that the number of non-contribution workers of basic endowment insurance for urban workers accounts for the number of insured workers in enterprise sector (\%), 2006-2014

Data source: data of payment number in 2009-2014 come from "China social insurance development annual report 2014", the other relevant data come from Ministry of Human Resources and Social Security of the People' Republic of China, and the data of the figure are calculated by author.

The Coverage Extension Will Enlarge the Obligation for Payment of Pension in the Future. The current extension could increase the revenue collection obviously. However, the growth of revenue collection today means more growth of obligation for payment of pension in the future. There are three reasons: firstly, any new to join the group in the future will receive a pension. The basic pension they will receive is the net indebtedness of basic endowment insurance system, because their contribution will be used to pay the pension for those who retire earlier than them. Moreover, the individual account pension they will receive may also not have sufficient assets accumulation, because the empty accounts formed by the embezzlement of personal account funds may not be able to be made up in time, and the fund's investment channels are sluggish, so it is difficult to achieve its value preservation and increment. Secondly, people who join basic endowment insurance for urban workers as a result of powerful extension are usually the middle and lower level workers with a lower average income level, and they tend to be beneficiaries of the income redistribution, that is to say, the more the groups to join, the more the country to finance. Thirdly, in order to promote the extension, some local governments take the preferential measures to enhance the system's attraction, such as reducing the contribution ratios of specific groups, which would reduce the revenue collection of system, but wouldn't reduce the future obligation for payment of pension accordingly. Of course, the emphasis here isn't to oppose the extension for fearing of future obligation for payment of pension, but to remind not to ignore the future risks because of the temporary benefits.

\section{Future Coverage Extension Policy and Government's Work Focus}

Future Coverage Extension Policy. The fundamental goal of extension is to make more workers and their families obtain basic old-age security from this system. So as long as there is still a large number of workers suitable for this system but now out of it, the current efforts to promote the extension should keep going. However, the extension must remain stable, neither for realizing the "achievement" of extension, nor for increasing the current revenue collection casually. The key criterion here is not to destroy the insurance characteristics of the system. Specifically, we should pay attention to the following two points: Firstly, the objects of the coverage extension should be the labors with a 
considerable contribution capacity. It is reluctant for the workers with very weak contribution capacity that try to absorb them into the system of basic endowment insurance for urban workers, and it is also harmful to the sustainable development of the system. Therefore, they should be put under the protection of the social assistance system. Secondly, the contribution ratios should be unified in the extension process. The use of preferential ratios for vulnerable groups is a harm to other employers and workers, and to the insurance characteristics and financial sustainability of the system.

Government Should Change Its Work Focus. With the coverage extension coming to an end, there is no longer a possibility to increase the revenue collection substantially just relying on the extension. In the meantime, with the arrival of the aging peak, the expenditure of basic endowment insurance for urban workers will inevitably grow rapidly. In this case, the Chinese government should shift its work focus to strengthen the financial sustainability of the system. Three jobs need to be completed: firstly, the basic pension should be paid by the social account independently, and the financing gap should be solved by financial subsidies and other measures. As for personal account, the stratiogic decisions should be made as quickly as possible, either making personal account fully funded and establishing effective investment management system as soon as possible or changing it into a "nominal account system" in law. Secondly, some key parameters should be adjusted at a right time. In particular, the statutory standard retirement age should be raised and the minimum contribution period should be prolonged. Thirdly, the pension funds should be enriched, and the investment management and supervision system should be improved. On the one hand, the central government and local government should develop scientific and rational systematic financing plan as early as possible, using their mastery of the natural resources, state-owned assets, fiscal revenue, foreign exchange reserves and other resources to establish some abundant special fund reserves. On the other hand, improving the investment management and supervision system of the central and local pension funds should be put on the agenda as soon as possible. Its core content is to establish the investment management systems of pension funds by both the central government and the provincial governments, and improve the corresponding supervision systems.

\section{Acknowledgments}

This work was financially supported by self-determined research funds of CCNU (Central China Normal University) from the colleges' basic research and operation of MOE ( CCNU16Z02007 ) .

\section{References}

[1] The State Council of China: Decision of Perfecting Basic Endowment Insurance System for Enterprise Employees [EB]. Retrieved from

http://www.gov.cn/zwgk/2005-12/14/content_127311.htm , 2005-12-14/2015-05-26

[2] Ministry of Human Resources and Social Security of the People' Republic of China: . Human Resources and Social Security Development Statistics Bulletin (2013)[EB]. Retrieved from http://www.mohrss.gov.cn/SYrlzyhshbzb/zwgk/szrs/tjgb/201405/t20140529_131147.html

[3] The State Council of China. The Twelfth Five Year Plan for National Economic and Social

Development of the People's Republic of China [EB]. Retrieved from

http://news.xinhuanet.com/politics/2011-03/16/c_121193916_19.htm

[4] The State Council of China. Notice of Forwarding and Approving the Outline of the "Twelfth Five-Year" Plan of Social Security to the Social Security System [EB]. Retrieved from http://www.gov.cn/zwgk/2012-06/27/content_2171218.htm , 2012-06-27/2015-05-28. 
[5] Zhu Dongmei: From the View of Payments Balance of Funds to See the Extension Needs of Pension Insurance and the Coping Stratiogies [J]. Labor and Social Security, Vol. 12 (2005), p. 33-36

[6] Wang Hongcai: Present Situation and Measures of the "Expansion "of Urban Basic Endowment Insurance in China [J]. Economic Research Herald, Vol. 11 (2012), p. 66-68

[7] Wang Xiaojun: Analysis on the Financial Sustainability of China's pension insurance system [J]. Market and Population Analysis, Vol. 2 (2002), p. 26-29

[8] Sun Yongyong, Shi Lei: The Main Sources and Countermeasures of the Financial Risk of the Basic Endowment Insurance System for Urban Works in China [J]. China Administn, Vol. 11 (2012), p. $30-35$

[9,10,11,12,13,15] Zheng Bingwen: China Pension Development Report 2014[M]. Beijing: Economic Management Press,(2014), p.15-16,p.13,p.16,p.16,p.18-19,p.51,p.75,p.78

[14] United Nations Population Division: United Nations Population Forecast 2050 China (1950-2050) [DB].

[15] Chen Weicheng, Guo Xisi. Evasion: Dilemma of China's Social Security System for the Aged [J]. Market and Demographic Analysis, Vol. 2 (2005), p. 53-56 